\title{
BIOÉTICA DAS INTUIÇÕES PIONEIRAS - PERSPECTIVAS NASCENTES AOS DESAFIOS DA CONTEMPORANEIDADE - II
}

\section{Bioethics of the pioneer intuition and rising perspectives connected to some challenges of contemporary}

\author{
Leo Pessini \\ Centro Universitário São Camilo, São Paulo, Brasil. \\ pessini@scamilo.edu.br
}

Resumo: Este artigo divide-se em duas seções. Nesta segunda seção são apresentadas e comentadas as três edições da Enciclopédia de Bioética (Encyclopedia of Bioethics), publicadas em 1978, 1995 e 2004, obra que espelha o desenvolvimento do campo da bioética. A partir da terceira edição prospectamos, juntamente com seu Editor-chefe, Stephen Post, alguns desafios da contemporaneidade e nos perguntamos sobre o futuro da bioética. Concluímos apontando que muitos dos desafios de hoje em relação ao meio ambiente e ecologia estão no coração do entendimento da bioética potteriana.

Palavras-chave: Bioética. Ciência. Religião. Enciclopédia.

\begin{abstract}
This article is divided in two sessions. In the 2nd part the reader is introduced in the referencial academic work for the field of bioethics - the Encyclopedia of Bioethics. Some discussions are made in respect to each one of the tree editions published so far (1978, 1995 e 2004), showing how the field evolved since the first edition of 1978. A special look is done on the 3rd edition, with the Editor-in Chief, Stephen Post, on the challenges for bioethics in the contemporary world. We conclude pointing out that the todady's challenges in relation to environment and ecology is in the heart of the potterian understanding of bioethics.
\end{abstract}

Key words: Bioethics. Science. Religion. Encyclopedia. \footnotetext{
fundamental para a bioética, é imperioso que consultemos a referência primordial, ou seja, a Enciclopédia de Bioética (Encyclopedia of Bioethics).
} 
Desde o surgimento do neologismo bioethics, com Potter, em 1971, esta obra mereceu três edições nos Estados Unidos da América do Norte (EUA), completamente revistas e atualizadas, em momentos distintos de evolução histórica da bioética: a primeira edição em 1978, a segunda em 1995 e a terceira em 2004. As duas primeiras edições tiveram como editor chefe Warren Thomas Reich, da Georgetown University, sendo que na terceira, o editor chefe é Stephen G. Post, da Case Western Reserve University. Neste artigo são apresentadas as definições de bioética nas três diferentes edições desta obra referencial. O que apresentamos a seguir, na sua substância, encontrase em grande parte no prefácio e introdução da segunda e terceira edições da Enciclopédia.

\section{A Enciclopédia de Bioética (EB)}

A partir de comentários de especialistas na área, Reich resume da seguinte forma o significado da Enciclopédia ao longo dos últimos 25 anos:

“...a primeira edição da EB teve um papel importantíssimo no estabelecimento do novo campo da bioética, formulou a mais ampla definição de bioética que foi aceita, definiu o objetivo do novo campo, apresentou a primeira organização de conhecimento e articulou modelos de ensino da bioética" (REICH, 1978).

Daniel Callahan, no final dos anos 1980, quando Reich iniciava o processo de criação da segunda edição da EB, comentou que além de ser uma ferramenta constante de uso como referência "a EB serviu como um importante documento central, provendo unidade, coerência e direção para o campo. Ninguém poderia ter isto junto a partir de uma simples consulta de livros e artigos que definem a maioria dos campos" (REICH, Op. cit.).

Reich considera que a primeira edição da EB cumpriu a grande função de desenhar o campo, enquanto a segunda edição começou a refletir o campo, ao mesmo tempo em que continua a função de desenhá-lo. É essencial que nenhuma destas funções contrastantes seja abandonada. À medida que o tempo passa, haverá sempre mais e mais pressão para que a EB simplesmente reflita e acuradamente resuma os desenvolvimentos em curso do campo da bioética, mas a responsabilidade pelo campo exige que a EB continue criativamente também a desenhá-lo. 


\section{Como Foi Concebida a Enciclopédia?}

Conforme Reich, foi o conceito "enciclopédia" que capturou a busca, composto por duas palavras gregas, Enkuklios paidéia. Tomou-se a palavra paidéia, que significa a educação formal do jovem nas artes e ciências, como um indicador da responsabilidade em criar uma coletânea abrangente do conhecimento, geral e específico, necessário à bioética, como um campo de aprendizagem e uma área de ação responsável nos níveis individual, social, político e profissional.

O termo enkuklios (enciclo), ou cíclico, significa "círculo de aprendizagem", no sentido de que devemos organizar a informação de tal maneira que uma pessoa não iniciada pode mover-se facilmente de um conjunto de informações para outro, deslocando-se em círculo, de artigo para artigo, buscando o conhecimento mais completo sobre um determinado tópico. O tamanho do círculo é determinado pelo interesse do pesquisador (REICH, Op. cit.).

A segunda edição é na verdade uma nova obra, incorretamente denominada de "edição revisada", representando um grande avanço em relação à versão original, segundo seu editor chefe. Foi um trabalho mais difícil que a primeira edição, em parte porque o campo da bioética mudou muito nos anos que vão desde os trabalhos preliminares da primeira edição, no início dos anos 1970, até o processo de elaboração da segunda edição, no início dos anos 1990. Ocorreram mudanças dramáticas no campo da bioética, não somente por causa dos avanços científicos, médicos e na dimensão legal, mas também a própria ética evoluiria muito nos anos subseqüentes à edição original da EB.

Para se ter uma idéia do trabalho desenvolvido na segunda edição vejamos, o que diz seu editor:

"Enquanto a primeira edição de 1978 tinha 315 artigos de 285 colaboradores em quatro volumes, a segunda edição, em 1995, expandiu para 464 artigos de 435 autores em cinco volumes. Somente alguns artigos clássicos da primeira. edição, elaborados por luminares intelectuais tais como Talcott Parson, Pedro Laín Entralgo (Espanha), Jay Katz e Joseph Kitagawa, foram transportados para a segunda edição da EB. Não tenho dúvida que a segunda. edição colocou a EB num novo e mais alto patamar, marcando um posição muito mais forte para o campo" (REICH, Op. cit.) 


\section{Contexto do nascimento da bioética na perspectiva dos autores da Enciclopédia}

Importante registrar o que foi dito em relação às origens da bioética. A palavra bioethics foi cunhada no início dos anos 1970 por biólogos com o objetivo de encorajar a reflexão pública e profissional em duas questões de urgência: 1) a responsabilidade em manter a ecologia generativa do planeta, da qual depende a vida e a vida humana; 2) as futuras implicações dos rápidos avanços nas ciências da vida em relação a potenciais modificações de uma natureza humana maleável.

Em seu livro pioneiro, intitulado Bioethics: bridge to the future, publicado em 1971, Van Rensselaer Potter discorreu sobre a biologia evolutiva, uma habilidade humana crescente de alterar a natureza e a natureza humana, bem como sobre as implicações de seu poder para o futuro global. Outros cientistas da vida naquele momento, tais como Bentley Glass, Paul Bert e Paul Ehrlich estavam entre os muitos interessados em refletir sobre a revolução biológica em relação à eugenia, à engenharia de novas formas de vida e ética da população. A bioética surge a partir de preocupações dos biólogos que se sentiram obrigados a refletir sobre o significado moral da biosfera e sobre as implicações fantásticas de suas descobertas e inovações tecnológicas.

Lado a lado a essa vertente que cunhou o silogismo bioethics e desenhou os estudos nesse campo a partir da discussão entre os cientistas da vida, emergiu o campo da ética médica, que era velho e novo ao mesmo tempo. Era velho no sentido de que os médicos desde sempre refletiram sobre os seus deveres profissionais com seus pares. E era novo, já que esta reflexão estava ocorrendo num diálogo aberto, com teólogos e filósofos, e muito atento com a preocupação pública, que relacionava os direitos civis e o declínio do valor atribuído à autoridade.

Essa discussão emergente, rapidamente envolveu todas as profissões da saúde. Os médicos ao abordar ética médica estavam conversando com a sabedoria acumulada de ética médica dos católicos, judeus e protestantes, bem como com filósofos da moral. Muitos filósofos, neste momento inicial, engajaram-se num diálogo mutuamente frutuoso e enriquecedor com pensadores religiosos. Tal diálogo não somente contribuiu para a vitalidade do campo, mas também refletiu a dinâmica de uma democracia liberal no início dos anos 1970, em que os cidadãos de todos os backgrounds e linhas de pensamento foram motivados para as questões morais importantes relacionadas com os cuidados da saúde, medicina, pesquisa e relação profissional-paciente.

A bioética, definida pela tradição da Enciclopédia, desenvolveu-se a partir 
destas duas linhas centrais de questões, trazidas pelos cientistas da vida e as novas questões éticas emergentes a partir dos avanços da medicina. Neste sentido, a obra integra os aspectos relacionados aos cuidados de saúde e à ética médica, sem perder de vista o contexto maior apresentado pelos cientistas da vida no início dos anos 1970, com inquietações ligadas ao ambiente e saúde pública.

\section{As Edições de 1978, 1995 e 2004}

\section{A primeira edição - 1978}

Em 1978, quando surgiu a primeira edição da Enciclopédia, a Bioética era ainda nova e relativamente indefinida. Nesta primeira edição, a bioética é entendida como sendo:

"O estudo sistemático da conduta humana no âmbito das ciências da vida e da saúde, enquanto essa conduta é examinada à luz de valores e princípios morais (...). A bioética abarca a ética médica, porém não se limita a ela. A ética médica, em seu sentido tradicional, trata dos problemas relacionados com valores, que surgem da relação médico-paciente. A bioética constitui um conceito mais amplo, com quatro aspectos importantes:

- Engloba os problemas relacionados aos valores que surgem em todas as profissões de saúde, inclusive nas profissões afins e aqueles vinculados à saúde mental;

- Aplica-se às pesquisas biomédicas e comportamentais, independente de influírem ou não de forma direta na terapêutica;

- Aborda uma ampla gama de questões sociais, relacionadas com a saúde ocupacional e internacional e com a ética do controle de natalidade, entre outras;

- Vai além da vida e saúde humanas, enquanto compreende questões relacionadas à vida dos animais e das plantas, por exemplo no que concerne às pesquisas em animais e demandas ambientais conflitivas" (REICH, Op. cit.).

Esta edição foi considerada como livro de referência do ano nos EUA em 1979 pela Associação Americana de Bibliotecas. Callahan em sua revisão crítica a denominou como sendo "uma suma de ética médica" e a Hastings Center Report como sendo "uma conquista incrível". No decurso dos anos 1980, com o surgimento de inúmeros programas em bioética e de humanidades médicas, a inserção da bioética nos currículos formativos de escolas 
profissionais, de graduação e pós-graduação, bem como o surgimento de sociedades acadêmicas, a EB tornou-se uma obra fundamental para referência e consulta, contribuindo muito para a vitalidade intelectual no campo.

Embora para quem esteja interessado na história da bioética seja sempre fascinante e importante ler esta primeira edição, o avanço das questões nas áreas tecnológica e ética, no final dos anos 1980, implicou na necessidade de revisar a obra. Como obra de referência, que trata da interface da biologia, tecnologia, cuidados em saúde e ética, torna-se rapidamente defasada devido aos rápidos desenvolvimentos e mudanças nos sistemas de saúde em todo mundo e ao surgimento de novas e importantes vozes na cena social. Embora em certos aspectos o movimento da bioética moderna tenha se iniciado nos EUA, ele já havia se enraizado em muitos países do mundo durante dos anos 1980, o que está refletido na segunda edição em 1995.

\section{A segunda edição - 1995}

A edição de 1995, com cinco volume, começou a ser planejada em 1990 e continuou sob a responsabilidade do mesmo editor da obra original. Foi realizado um extraordinário trabalho de inclusão da história da ética médica, do movimento moderno da bioética, de pensadores europeus, de ética religiosa e da filosofia moral, além das questões clínicas. Como é compreendido este novo campo do saber humano - a bioética - nesta segunda edição da Enciclopédia? Assim define Reich:

"Bioética é um neologismo derivado das palavras gregas bios (vida) e ethike (ética). Pode-se defini-la como sendo o estudo sistemático das dimensões morais - incluindo visão, decisão, conduta e normas morais das ciências da vida e da saúde, utilizando uma variedade de metodologias éticas num contexto interdisciplinar" (REICH, 1995).

Nesta edição não se usa a expressão "princípios". Reich explica que na primeira edição o termo foi utilizado no sentido de fonte, porque se tinha como objetivo uma definição que permitisse o campo da bioética aberto a qualquer metodologia. Especificamente se fazia necessária uma definição que encorajasse o uso das fontes da metaética e do conhecimento moral normativo, que não eram de uso corrente nos anos 1970, quando o modelo deontológico/teleológico da ética rule-based, fundamentado em preceitos e regras, era bem mais popular. Assim, a palavra "valores" foi incluída na primeira definição para acentuar essa abertura a todas as fontes do 
conhecimento moral. Porém, logo após a primeira edição da EB, um sentido reducionista de "princípios" começou a ser dominante, isto é, uma definição concisa de uma regra ou norma de comportamento, como um guia de ação. Conseqüentemente, para fugir deste reducionismo a definição da segunda edição não utiliza o termo princípios e fala de "uma variedade de metodologias éticas num contexto multidisciplinar" (REICH, Op. cit).

As dimensões morais examinadas pela bioética estão constantemente evoluindo, mas tendem a enfocar as questões maiores, tais como: Qual é, ou deve ser, a visão moral de pessoa ou de sociedade? Que tipo de pessoa devemos ser, ou que tipo de sociedade necessitamos construir? O que deve ser feito em situações específicas? Como vivermos harmoniosamente?

Tentando responder a tais questionamentos, na segunda edição foram incluídas inúmeras questões novas, entre elas, apontamos como de maior relevância: relação profissional-paciente; bioética e ciências sociais; cuidados em saúde; fertilidade e reprodução humana; pesquisa biomédica e comportamental; historia da ética médica, saúde mental e questões comportamentais; sexualidade e gênero; sobre a morte e o morrer; genética e ética da população; doação e transplante de órgãos; bem-estar e tratamento dos animais; meio ambiente; códigos; juramentos; e outras inúmeras diretrizes éticas de organismos nacionais e internacionais.

\section{A terceira edição - $\mathbf{2 0 0 4}$}

Após uma trajetória de pouco mais de três décadas, a bioética angariou reconhecimento na área científica e pública. Com o passar dos anos 1990, a Enciclopédia novamente precisou passar por uma completa revisão e atualização. Reich, profundamente envolvido num novo projeto sobre a história do cuidado, decide não participar no processo de preparação da terceira edição. Indica para ser editor chefe desta nova versão, seu assistente Stephen Garrard Post, ligado ao Departamento de Bioética da Faculdade de Medicina da Case Western Reserve University (POST, 2005).

Segundo Post, a definição de bioética de 1995, como sendo o exame moral interdisciplinar e ético das dimensões da conduta humana nas áreas das ciências da vida e da saúde, dá forma à terceira edição, continuando a ampliar os tópicos da edição de 1995. Nesta mais recente versão da Enciclopédia existem 110 novos verbetes e aproximadamente o mesmo número de novos artigos que aparecem sob os títulos antigos. Portanto, metade da terceira edição é completamente nova, enquanto que a outra metade consiste de artigos revistos e atualizados da edição anterior, pelo próprio autor na maioria das vezes, quando isto foi possível. 


\section{Novos Tempos - Questões Emergentes São Enfatizadas}

Na terceira edição é incluída uma ampla gama de novos assuntos que vão desde o bioterrorismo, holocausto, imigração, questões éticas de saúde humana, nutrição e hidratação artificiais, até questões éticas relacionadas ao diagnóstico e tratamento em oncologia, demência, diálise renal e ordens para não reanimar. Além disso, é apresentada uma série de artigos sobre clonagem e pediatria. Questões tais como reprodução e fertilidade, transplantes de órgãos e tecidos, sobre a morte e o morrer, teoria ética, bioética e políticas públicas (legislação), saúde mental, genética, religião e ética, foram completamente revistas.

Além destas, uma área nova de reflexão, extremamente delicada e sensível na contemporaneidade, é a questão da ética dos negócios na área dos cuidados da saúde, que mereceu vários verbetes. Dentre eles elencamos: seguros de saúde, conflitos de interesse, políticas públicas de saúde nos EUA, ética nos serviços de administração da saúde, ética organizacional nos cuidados da saúde, lucro e comercialização, entre outros. A abordagem destas questões na EB cresceu a partir da preocupação que surgiu nos anos 1990, diante das transformações da área dos cuidados de saúde em um negócio, visando basicamente o lucro econômico.

Quando se fala de conflitos de interesse, é bom lembrar que, especialmente nos centros da academia médica das maiores universidades, de forma crescente, os próprios bioeticistas aceitaram recompensas financeiras lucrativas de companhias farmacêuticas e de empresas de biotecnologias. Embora isto não signifique que alguns bioeticistas não sejam mais livres para pensar determinadas questões éticas, significa, outrossim, que eles estão sujeitos à várias pressões e devem ser totalmente transparentes de qualquer interesse financeiro que possa estar influenciando suas opiniões. Reich enfatiza que, "de todos os campos, a bioética deve manter-se longe de qualquer mancha por conflito de interesse, uma vez que sua credibilidade pública está sempre em risco" (REICH, Op. cit.).

Uma outra área que também mereceu um cuidado especial e que nesta última edição ganha uma amplitude maior, são os artigos de fundo sobre teoria ética, bem como novos textos que lidam com as abordagens éticas religiosas. No âmbito da teoria ética destacamos, entre outros: direito de consciência, contratualismo e bioética, comitês de ética, consultoria ética, dignidade humana, direitos humanos, status moral, principialismo, utilitarismo e bioética, valores e cuidados de saúde. No âmbito das abordagens 
éticas religiosas foram acrescentadas reflexões sobre: autoridade nas tradições religiosas, bioética no cristianismo, aspectos religiosos da circuncisão, amor compassivo, Testemunhas de Jeová e a recusa à transfusão de sangue, bioética e os Mórmons.

Além destes artigos de fundo sobre teoria ética, bioética e religiões, acrescentam-se verbetes sobre antropologia e bioética. Em termos de América Latina, nesta última edição, sob o verbete, História da Ética Médica nas Américas, José Alberto Mainetti, da Argentina, fala do movimento da bioética no continente, sublinhando suas questões maiores: reprodução, a morte e o morrer, ética da pesquisa, ética da saúde e meio ambiente. Enfatiza que uma macro-ética da saúde ou saúde pública está sendo proposta como alternativa à tradição anglo-americana de micro-ética e de ética clínica. Maior ênfase deve ser colocada na importância da medicina social, na questão da justiça e eqüidade na alocação de recursos, bem como no acesso aos serviços de saúde. Mainetti lembra que dois congressos mundiais de bioética foram realizados na América Latina, um em Buenos Aires em 1994 e o outro em Brasília, em 2002, o qual teve como tema: Bioética, poder e injustiça. Na visão de Mainetti, a América Latina não perdeu a esperança de ser o continente da justiça e por isso: "a revolução bioética sumarizada num bios de alta-tecnologia e por um ethos individualista, deve ser complementado na América Latina por um bios humanista e um ethos comunitário". Duas questões instigantes são levantadas pelo editor, o pluralismo e o discurso público e o pós-humanismo.

\section{O Pluralismo e Discurso Público}

A tradição da Enciclopédia apresenta uma contribuição instrutiva para o futuro da bioética na academia, uma vez que inclui uma ampla variedade de vozes que abordam as questões de bioética, consistentes com a diversidade e pluralismo típico das democracias liberais. Para que a área acadêmica da bioética permaneça relevante e criativa, é sábio incluir representantes de todo este espectro de posicionamentos.

Como Alasdair MacIntyre afirmou, cada sistema de filosofia ou ética religiosa tem suas próprias verdades fundacionais a respeito do que constitui a natureza humana e o bem humano, seus contextos históricos e questões únicas, bem como seus limites conceituais inerentes. A bioética é conseqüentemente aprimorada pelo diálogo com as diferentes tradições de pensamento, sejam elas de vertente secular ou religiosa, refletindo a diversidade da esfera pública. Tal diálogo exige um conjunto de virtudes em relação ao 
discurso global, como o respeito mútuo, a tolerância, civilidade e abertura para mudar a partir da clarificação dos fatos empíricos e da persuasão dos outros. $\mathrm{O}$ monismo, ou seja, a visão de que somente uma voz é válida - seja secular ou religiosa - elimina o diálogo, inibe a participação plena e compromete o avanço conceitual. Na visão de seu mais recente editor, a EB é:

“...uma obra única porque sempre incluiu muitas vozes e tradições num esforço para incentivar o diálogo, evitar o estreitamento do campo e engajar uma ampla leitura internacional. Esta edição, como as anteriores, contempla abordagens inter-culturais, a história completa da bioética, ética religiosa comparativa e filosófica bem como as perspectivas globais. Os artigos sobre a história da ética médica são exemplos do esforço para destacar o grau em que nossas teorias contemporâneas de ética e bioética evoluem a partir de um determinado contexto social, cultural-religioso e histórico. Contudo, os artigos históricos sobre a 'época contemporânea', nos dão importantes informações sobre o desenvolvimento de questões tais como ética na China, o suicídio assistido na Holanda e a legislação sobre a morte cerebral no Japão" (POST, Op. cit).

\section{O Pós-humanismo e o Anti Pós-humanismo}

Importante destacar novos artigos que refletem sobre o transumanismo e pós-humanismo, cibernética, clonagem, dignidade humana, embrião e feto, pesquisa com células tronco-embrionárias, tecnologia médica e melhoramento humano, nanotecnologia, o envelhecer e o idoso, intervenções antienvelhecimento e questões ético-sociais. Coletivamente esses artigos acentuam a questão do que significa ser humano. O pós-humanismo, diz o editor da Enciclopédia:

“...é um puro cientificismo que propõe alterações fundamentais na natureza humana, superando os limites biológicos e transcendendo o humano pela tecnologia. O pós-humanista tem como objetivo desacelerar ou até mesmo parar o processo de envelhecimento, mas somente como uma pequena parte de uma visão maior de re-engenheirar a natureza humana, e portanto criar biológica e tecnologicamente seres humanos superiores, que nós seres humanos de hoje desenharemos para o amanhã. Como tal, os pós-humanos, não serão mais humanos" (POST, Op. cit.). 
Esta questão do pós-humanismo ou do transumanismo vem sendo explorada na atualidade por Francis Fukuyama, que gerou polêmica mundial com a sua obra O fim da história e o último homem. Uma de suas mais recentes publicações é justamente sobre esta temática, Nosso futuro póshumano: conseqüências da revolução da biotecnologia. Fukuyama fala dos transumanistas, que pretendem nada menos do que libertar a raça humana de seus limites biológicos:

"Para os transumanistas, os seres humanos precisam assumir o controle de seu destino biológico, desvinculá-lo do cego processo evolutivo de variação aleatória e adaptação, e assim inaugurar uma nova era como espécie. (...) Todavia, o princípio básico do transumanismo - o de que um dia usaremos a biotecnologia para nos tornar mais fortes, mais inteligentes, menos violentos, assim como para ampliar nossa vida será de fato tão bizarro? Uma espécie de transumanismo já está implícita em grande parte do programa de pesquisas da biomedicina contemporânea. Novos procedimentos e tecnologias que estão surgindo em laboratórios de pesquisa e hospitais - como medicamentos que alteram o humor, substâncias que aumentam a massa muscular ou apagam seletivamente as memórias, exames genéticos pré-natais, terapia genética - podem ser facilmente empregados tanto para aperfeiçoar a espécie como para aliviar ou curar doenças" (FUKUYAMA, 2005).

A genética, a nanotecnologia, a clonagem, a cibernética e as tecnologias de computador são parte de uma visão pós-humana, que inclui até a idéia de formar uma mente computadorizada, livre da carne mortal e, portanto, imortalizada. Os pós-humanistas não acreditam que a biologia seja um destino, mas antes algo que deve ser superado, porque segundo eles, não existe "lei natural", mas somente maleabilidade humana e liberdade morfológica. Enfim, a ciência está avançando tão rapidamente, que necessitamos de sérias discussões para distinguir entre as transformações que são salutares e as que são destrutivas.

Para uma mente pós-humanista a natureza humana, tal como a conhecemos, é um mero obstáculo a ser superado. Para alguns, a ambição dos pós-humanistas em criar um novo pós-humano, que não é mais humano, é uma atitude arrogante, pretenciosa e que desconsidera a apreciação pela dignidade humana natural. Para outros, todos estes esforços são vistos como potencial para um progresso no desenvolvimento destas forças tecnológicas: 
"A nossa época está começando a considerar seriamente possibilidades de "trans-humano" através de melhoramentos biotecnológicos das capacidades humanas biológicas tais como, tempo de vida, tipo de personalidade e inteligência. Qual era o status da generatividade altruística que Erik Erikson associou com a velhice a medida que os seres humanos aventureiramente envidam esforços para alterar o tempo de vida? Será a compaixão deixada de lado em favor da busca biotecnológica de músculos mais fortes, maior longevidade, disposições de felicidade e beleza permanentes? Ou, seriam o cuidado e a compaixão que estão em nós, 'o último aperfeiçoamento humano'? Os leitores da Enciclopédia são encorajados a refletir sobre tais questões e tirar suas próprias conclusões" (POST, Op.cit.).

Vale destacar o que é dito por Post no final da introdução da obra, a respeito do discurso civil e da humanidade:

"Por causa das questões que a bioética lida serem profundamente relevantes para o futuro da natureza, natureza humana, e para a área da saúde, elas são freqüentemente contenciosas. Contudo, na dialética entre objetivismo moral e relativismo moral, enquanto muitas destas questões permitem uma resolução plausível, existem outras para as quais não emerge nenhuma resolução. Tolerância, civilidade, respeito e a vontade sincera de engajamento sério com a visão dos outros que tem diferentes tradições, sejam estas seculares ou religiosas, são virtudes e hábitos mentais, necessários. A bioética é inevitavelmente sujeita às críticas daqueles que acreditam que as respostas para inúmeras questões novas trazidas pelas revoluções biológica e dos cuidados de saúde são imediatas e simplesmente fáceis. Mas afinal, o que é um bom profissional da ética, seja este secular ou religioso, senão aquela pessoa que levanta uma nova questão que ninguém tinha antes formulado e que propicia um debate aprofundado como uma alternativa à superficialidade?" (POST, Op.cit.).

\section{Conclusão}

Como apresentado na primeira seção deste artigo, nas origens da bioética temos o encontro da intuição original de Potter com a obra referencial do campo que é a Enciclopédia de Bioética. Curiosamente no curso histórico das origens, a perspectiva de Bioética de Georgetown, - bioética médica e 
clínica - que vai produzir a Enciclopédia de Bioética, praticamente ignorou Potter na sua perspectiva da ética global e da sustentatilidade ecológica para garantir o futuro da vida no planeta Terra. Este encontro contribuiu para o desenvolvimento da reflexão bioética dos últimos anos, na compreensão que temos hoje de bioética.

A reflexão potteriana se antecipa a toda a problemática ecológica de hoje, e tem muita sintonia com a causa ecológica das Nações Unidas e de ilustres ativistas na área, entre outros, Mikahil Gorbachev, que identifica três grandes desafios a serem enfrentados em nosso tempo. O primeiro trata-se da necessidade de manter a paz no mundo; a comunidade internacional tem de estar unida também na luta contra o terrorismo que não pode ser justificado por nenhuma consideração política ou moral. O segundo desafio é a luta contra a pobreza no mundo; como pode o "milhão dourado" de pessoas bafejadas pela sorte permanecer indiferente diante do espetáculo da miséria em que se debate a metade da população do planeta, reduzida a viver com um ou dois dólares por dia, passando fome todos os dias, sem acesso à água potável e sem condições decentes de higiene? O terceiro desafio identificado está ligado ao meio ambiente; entramos em sério conflito com o nosso próprio habitat - com a mãe natureza. Esses três desafios são interdependentes. Sem combater a pobreza serão inúteis também todas as medidas ecológicas. Mas se não nos preocuparmos com a ecologia, todos esforços para construir um mundo mais justo estarão fadados ao fracasso e nossos descendentes terão que pagar pelo nosso comportamento insensato e depredador da natureza. A própria vida na Terra corre o risco de desaparecer, tornando-se somente um episódio efêmero na história do universo.

Os três desafios propostos não dizem respeito somente aos governos e às organizações internacionais, mas a cada um de nós. Chegou a hora de todo cidadão do planeta pensar na contribuição pessoal que pode dar para essa tarefa comum:

"Somos responsáveis, diante das gerações futuras, pela conservação da vida na Terra. (...) Hoje, a humanidade precisa de uma nova filosofia de vida, de uma nova ética que cristalizará os valores fundamentais, comuns a todas as tradições religiosas, uma ética baseada no consenso entre as nações e os povos do mundo" (GORBACHEV, 2003).

Gorbachev nomeia este projeto como sendo um processo de elaboração de uma ética global e conclui dizendo: "a exemplo do grande escritor 
americano William Faulkner, eu me recuso a aceitar a possibilidade do fim da humanidade, quaisquer que sejam as provações que tenha que enfrentar. Este é o meu credo de um incorrigível otimista" (GORBACHEV, Op. cit). Lembrando a Carta Terra, da qual foi um dos principais líderes em todo o processo, ele almeja que nosso tempo seja lembrado "pelo despertar de uma nova reverência diante da vida, por um compromisso firme de alcançar a sustentabilidade, pela rápida luta pela justiça, pela paz e pela alegre celebração da vida" (GORBACHEV, Op. cit).

Neste momento em que a UNESCO acaba de aprovar a Declaração Universal de Bioética e Direitos Humanos deve-se considerar que promover o respeito à biodiversidade e desenvolver a responsabilidade para com a biosfera passam, definitivamente, a fazer parte da agenda da bioética. A proteção da biodiversidade e da biosfera em que o ser humano vive, está entre os princípios fundamentais a serem discutidos pela bioética.

Finalizamos com um conceito de bioética apresentado pela Carta de Buenos Aires, elaborada por um grupo de especialistas latino-americanos da área, em novembro de 2004:

"Convencidos de que a bioética não se ocupa somente dos problemas éticos originados do desenvolvimento científico e tecnológico, mas também das condições que tornam o meio ambiente humano ecologicamente equilibrado na biodiversidade natural... e de todos os problemas éticos relacionados ao cuidado da vida e da saúde... (a bioética) tem como pressuposto básico o conceito de saúde integral entendido na perspectiva biológica, psicológica, social e ambiental, como o desenvolvimento das capacidades humanas essenciais que viabilizem uma vida longeva, saudável e alcançável por todos, o quanto seja possível" (CARTA DE BUENOS AIRES, 2004).

Levando em consideração perspectivas novas dos últimos Congressos Mundiais, vemos que a bioética vai avançando globalmente (geograficamente) ampliando sua compreensão epistemológica, bem como sua abrangência temática, enfrentando os desafios emergentes e sinalizando prioridades a seguir. Todo o processo dos seis congressos mundiais realizados num curto espaço de tempo, apenas doze anos, no final e início de milênio, que precisa ser visto, analisado, em conjunto. Não é saudável tomar apenas um evento de forma isolada, se quisermos entender de onde viemos e para onde estamos caminhando. 
Potter lá nas origens da bioética, na década de 1970, se antecipa e aponta para um dos maiores desafios que a humanidade tem neste início de milênio: garantir o futuro da vida no planeta Terra. Resgatarmos sua contribuição intelectual para o campo da bioética é uma questão de justiça histórica. Foi a tentativa deste texto. É sempre saudável voltarmos às origens e como diz T. S. Eliot:
"Não cessaremos de explorar,
e no final de toda nossa busca
chegaremos onde começamos
e conheceremos o lugar pela primeira vez!"

\section{Referências Bibliográficas}

CARTA DE BUENOS AIRES. Revista Brasileira de Bioética 1 (3): 317, 2005.

FUKUYAMA, F. Nosso futuro pós-humano: conseqüências da revolução da biotecnologia. Rio de Janeiro, Rocco, 2003.

. Ameaça à condição humana: não usar a biotecnologia para brincar de Deus. Veja, ano 38, n. 1, 5 janeiro de 2005: 80.

GORBACHEV, M. Meu manifesto pela Terra. São Paulo, Planeta, 2003.

POST, SG (Editor-in-Chief). Encyclopedia of bioethics. Macmillan, Dalle. 3rd ed; 2004.

POTTER, VR. Bioethics: the bridge to the future. New Jersey, Prentice-Hall, Inc, Englewood Cliffs, 1971.

REICH, WT. Shaping and mirroring the field: the encyclopedia of bioethics. In: WalterJK \& Klein EP. (Eds). The story of bioethics: from seminal works to contemporary explorations, Washington, Georgetown University Press, 2003.

REICH, WT (Editor-in-Chief). Encyclopedia of bioethics. Nova York, Macmillan, 1978.

REICH, WT (Editor-in-Chief). Encyclopedia of bioethics. Nova York, Macmillan, 1995.

Recebido em 22/07/2005

Aprovado em 18/10/2005

Retificação: na edição passada o título da primeira parte desse artigo deve ser lido como: "Bioética das intuições pioneiras - perspectivas nascentes aos desafios da contemporaneidade". 